\title{
Temporal heterogeneity in aerosol characteristics and the resulting radiative impacts at a tropical coastal station - Part 2: Direct short wave radiative forcing
}

\author{
S. Suresh Babu ${ }^{1}$, K. Krishna Moorthy ${ }^{1}$, and S. K. Satheesh ${ }^{2}$ \\ ${ }^{1}$ Space Physics Laboratory, Vikram Sarabhai Space Centre, Trivandrum, India \\ ${ }^{2}$ Centre for Atmospheric and Oceanic Sciences, Indian Institute of Sciences, Bangalore, India
}

Received: 2 November 2006 - Revised: 23 August 2007 - Accepted: 18 October 2007 - Published: 29 November 2007

\begin{abstract}
Seasonal distinctiveness in the microphysical and optical properties of columnar and near-surface (in the well mixed region) aerosols, associated with changes in the prevailing synoptic conditions, were delineated based on extensive (spread over 4 years) and collocated measurements at the tropical coastal location, Trivandrum $\left(8.55^{\circ} \mathrm{N} ; 76.97^{\circ} \mathrm{E}\right.$, $3 \mathrm{~m}$ a.m.s.l.), and the results were summarized in Part 1 of this two-part paper. In Part 2, we use these properties to develop empirical seasonal aerosol models, which represent the observed features fairly accurately, separately for winter monsoon season (WMS, December through March), intermonsoon season (IMS, April and May), summer monsoon season (SMS, June through September) and post monsoon season (PMS, October and November). The models indicate a significant transformation in the aerosol environment from an anthropogenic-dominance in WMS to a naturaldominance in SMS. The modeled aerosol properties are used for estimating the direct, short wave aerosol radiative forcing, under clear-sky conditions. Our estimates show large seasonal changes. Under clear sky conditions, the daily averaged short-wave TOA forcing changes from its highest values during WMS, to the lowest values in SMS; this seasonal change being brought-in mainly by the reduction in the abundance and the mass fraction (to the composite) of black carbon aerosols and of accumulation mode aerosols. The resulting atmospheric forcing varies from the highest, (47 to $53 \mathrm{~W} \mathrm{~m}^{-2}$ ) in WMS to the lowest (22 to $26 \mathrm{~W} \mathrm{~m}^{-2}$ ) in SMS.
\end{abstract}

Keywords. Atmospheric composition and structure (Aerosols and particles; Biosphere-atmosphere interactions; Transmission and scattering of radiation)

Correspondence to: K. Krishna Moorthy

(krishnamoorthy_k@vssc.gov.in)

\section{Introduction}

Radiative forcing due to atmospheric aerosols and the consequent climate impact remains largely uncertain due to uncertainties in aerosol models used in climate models (IPCC, 2001). These uncertainties are largely due to inadequate information on the aerosol characteristics at regional level as well as the inadequacy with which the available models represent the spatio-temporal heterogeneity (Schwartz and Andreae, 1996; Kaufman et al., 2002; Penner et al., 2002; Takemura et al., 2002; Kinne et al., 2003; Solomon et al., 2006). Unlike greenhouse gases (GHGs), which are uniformly mixed, aerosols are specific to regions and are strongly controlled by the source and sink effects, microphysics, and long-range transport. Changes in these arise also due to large-scale atmospheric dynamics. Recent studies have shown that the inclusion of aerosol effects in climate model calculations can improve the agreement with observed spatial and temporal temperature distributions (Hansen et al., 1997). It is thus important to establish a sound observational base for estimating the aerosol radiative forcing as well as its spatio-temporal variations.

Aerosols are, generally, believed to offset, at least partly, the global warming due to GHGs (Boucher and Haywood, 2001). This is attributed mainly to the scattering aerosols such as sulphates, which backscatter the down-welling solar radiation and indirectly change the cloud albedo and lifetime (Charlson et al., 1992; Twomey et al., 1984). Aerosols, whether scattering or absorbing, reduce the net short-wave radiation at the surface. However, absorbing aerosols absorb the solar radiation leading to heating of the atmosphere and if this occurs within the clouds, might lead to cloud burn off (Ackerman et al., 2000). All these are expected to slow down the hydrological cycle, reduce evaporation from the surface, and hence cloud formation (Lelieveld et al., 2001).

Published by Copernicus Publications on behalf of the European Geosciences Union. 
There are several global modeling and observational studies on the global radiative effects of a mixture of scattering and absorbing (sulfate and carbonaceous) aerosols (Haywood et al., 1997; Haywood and Ramaswamy, 1998; Penner et al., 1998; Andreae et al., 2005; Wild et al., 2005). In addition, in the recent years, several regional experimental studies focused to India and adjoining regions of Asia to characterize the aerosols and to assess their radiative impacts at a regional scale (Satheesh et al., 1999; Lelieveld, et al. 2001; Huebert et al., 2003; Vinoj et al., 2004; Girolamo et al., 2004; Moorthy et al., 2005; Tripathi et al, 2005; Niranjan et al., 2005; Ganguly et al., 2006). However, majority of these studies were conducted either over oceans or were largely weighed by the fair-weather season. All-weather and longterm observational data have only rarely been used in impact assessment. Studies over land are much more sparse compared to ocean, despite that absorbing aerosols over land with higher surface reflectance would enhance the atmospheric forcing (Haywood and Ramaswamy, 1998). They also absorb more solar radiation when located above or near the top of clouds than when they are located below (Keil and Haywood, 2003). In this paper, which is Part 2 of a two-part paper, we examine how the seasonal changes in aerosol microphysical properties modify the short-wave radiative forcing at the tropical coastal station (Trivandrum, $8.55^{\circ} \mathrm{N}, 76.97^{\circ} \mathrm{E}$, $3 \mathrm{~m}$ a.m.s.l.) based on long-term and collocated measurements of the properties of atmospheric aerosols and their seasonal distinctiveness as discussed in Part 1 of this paper.

\section{Estimation of aerosol radiative forcing - methodology}

By definition, the aerosol direct short-wave (solar) radiative forcing (DRF) is the change $(\Delta F)$ in the radiation flux $(F)$ either at the surface $(S)$ or at the top of the atmosphere (TOA), respectively without and with the aerosol particles in the atmosphere (Russell et al., 1999; Podgorney et al., 2000; Yu et al., 2001; Babu et al., 2002; Xu et al., 2003).

$(\Delta F)_{S, \mathrm{TOA}}=\left(F_{N A}\right)_{S, \mathrm{TOA}}-\left(F_{A}\right)_{S, \mathrm{TOA}}$

where $F_{N A}$ and $F_{A}$, respectively, correspond the short wave fluxes without and with aerosols, and the subscripts $S$ and TOA refer to the earth's surface and TOA, respectively. A negative value of $\Delta F_{\mathrm{TOA}}$ implies that the presence of aerosols results in an increase in the radiation lost to the space (by enhanced backscattering) leading to a cooling in the earth-atmosphere system, while its positive value implies an atmospheric warming. At the surface, the aerosol forcing $\left(\Delta F_{S}\right)$ will always be negative because aerosols reduce the surface reaching solar radiation. The difference between the two (called the atmospheric forcing) is expended in heating the atmosphere.

$(\Delta F)_{\mathrm{Atm}}=(\Delta F)_{\mathrm{TOA}}-(\Delta F)_{S}$

In order to compute the radiative forcing of aerosols, an appropriate aerosol model is needed to generate the input parameters for the radiation model. The accuracy of the computed aerosol forcing relies mainly on how closely this aerosol model represents the observed features. A realistic model should thus need information on the chemical composition and relative concentrations of each major species in the composite aerosol system, in addition to the size distribution, nature of mixing, and altitude profile. However, when the observations have limitations on such elaborated information, semi-empirical approaches are widely used (Satheesh et al., 1999; Podgorny et al., 2000; Lelieveld et al. 2001; Babu et al., 2002; Conant et al., 2003; Markowicz et al., 2003; Vinoj et al., 2004; Moorthy et al., 2005). In this approach, a model that would be a reasonable representation of the study region is adapted, from those available in the literature (e.g., Hess et al., 1998), as a zero order approximation and the available observations are used as anchoring points. The model parameters are then fine-tuned until a closure is obtained with the measurements (Satheesh and Srinivasan, 2006).

The inputs for estimating aerosol DRF are spectral Aerosol Optical Depth (AOD,); spectral single scattering albedo (SSA, $\omega_{\lambda}$ ), and the scattering phase function $(P(\theta)$ ). In our study, the spectral AODs came directly from the Multi Wavelength Radiometer (MWR) measurements in the wavelength range 380 to $1025 \mathrm{~nm}$, while SSA and $P(\theta)$ are inferred from the models that are constructed following the methodology described above. The aethalometer provided mass concentration of aerosol $\mathrm{BC}$ following optical absorption technique with a typical uncertainty of $20 \%$ (details are given in Part 1), while the QCM yielded the mass concentrations of the composite (total) aerosols in the size range 0.05 to $25 \mu \mathrm{m}$ in 10 size bins with an average uncertainty of $15 \%$. From the ratio of the mass concentration of $\mathrm{BC}$ to that of the composite aerosols, $\mathrm{BC}$ mass fraction $\left(F_{\mathrm{BC}}\right)$ is estimated which has an uncertainty of $25 \%$. For modeling the unmeasured aerosol characteristics we relied upon the Hess et al. (1998) OPAC (Optical Properties of Aerosols and Clouds) models, (for size distribution, phase function, and refractive indices corresponding to the mean relative humidity conditions for each season). For hygroscopic aerosols, the mode radius increases with increasing RH, while total number remains invariant. The refractive index of humid aerosols decreases, and this change has been calculated following the volume weighting formula (Shettle and Fenn, 1979). The OPAC permits up to eight values of relative humidity $(0 \%, 50 \%, 70 \%, 80 \%$, $90 \%, 95 \%, 98 \%$, and $99 \%$ ) for the calculations of aerosol optical properties from given size distributions and refractive indices and we used the value closest to the seasonal mean estimated from regular measurements at the site. The Hess et al. (1998) model deals with optical properties for 10 aerosol species such as water insoluble, water soluble, BC (soot), sea-salt (accumulation and coarse mode), mineral dust (nucleation, accumulation, coarse mode), mineral dust (transported) and considers them as externally mixed spherical particles, forming the composite aerosols. Pilinis et al. (1995) have shown that the nature of the state of mixing (internal or 
external) of similar sized aerosols is not very significant on short wave radiative forcing when the particles are predominantly of scattering nature. For the Indian Ocean Experiment (INDOEX) aerosol model, the global fluxes at the surface under clear skies, calculated for both externally and internally mixed aerosols were found to agree within $0.5 \%$ (Satheesh et al., 1999; Podgorny et al., 2000). However, recent studies have suggested that if one aerosol species is in a mixed state with another species in a core-shell structure, then the radiative impact could be significantly different than those of the externally mixed or internally mixed cases (Chandra et al., 2004). In a global modeling study where the BC is treated as a core in an internal mixture, Jacobson (2001) reported that the $\mathrm{BC}$ forcing is $50 \%$ higher than the forcing obtained with the externally mixed case and $40 \%$ lower than the forcing obtained with the internally mixed (volume mixture) case. He pointed out further that the internal mixing model is physically inconsistent for small $\mathrm{BC}$ particles, which do not dissolve. Based on observation and modeling Chandra et al. (2004) reported large difference in radiative forcing (by a factor of three) for different state of mixing of aerosols. Based on a more detailed treatment, Bond et al. (2006) suggested that much of the enhanced absorption due to internal mixing is artificial and would not be replicated by real particles. (In the present study the exact nature of the mixing state of ambient aerosols over TVM was unknown and this could form a separate study for the future.)

In our study, based on the geographical location and airmass types, we chose six aerosol types from the Hess et al. (1998) and assumed them as externally mixed spherical particles forming the composite aerosols. These are water soluble (WSC), insoluble (INS), BC (soot), sea salt accumulation (SSM), sea-salt coarse mode (SSC), and transported mineral dust (TMD). The soluble category includes sulfates, nitrates, and particulate organic matter, the optical and hygroscopic properties of which are considered to be similar to sulfates (Chin et al., 2002), while BC category includes absorbing black carbon. The first three species are believed to be mostly arising from anthropogenic activities. Sea-salt and transported mineral dust (which is transported over long distances and hence has a very low amount of large particles) are basically the natural species. Both coarse and accumulation modes of sea-salt are important for Trivandrum due to its coastal nature and seasonally varying winds. The number densities of each of the above species are varied while maintaining the $\mathrm{BC}$ mass-mixing ratio $\left(F_{\mathrm{BC}}\right)$ (ratio of the mass concentration of $\mathrm{BC}$ to that of the composite aerosols) as anchoring point, such that; (i) the spectral AODs reestimated from the resulting composite aerosol model match with the AOD spectra from measurements (using the multiwavelength radiometer, MWR, described in Part 1) over its entire wavelength range ( 380 to $1025 \mathrm{~nm}$ ) within the measurement uncertainties and (ii) the Angstrom wavelength exponent $\alpha$ estimated using the model agreed with those from the measurements (MWR) with in 5\% (Moorthy et al., 2005;
Satheesh and Srinivasan, 2006). The ambient RH is selected as the seasonal mean value prevailed at the site (from actual measurements). Once this closure is achieved, the SSA $(\omega)$ and phase function $P(\theta)$ of this model are computed using the OPAC as a function of $\lambda$ for the spectral region 0.25 to $4 \mu \mathrm{m}$. The estimated values of single scattering albedo $(\omega(\lambda))$ and phase function $(P(\theta))$, along with the appropriate surface albedo, are incorporated into the SBDART (Santa Barbara DISORT Atmospheric Radiative Transfer) code along with the measured AOD and $\alpha$ to compute the TOA and surface fluxes, with and with out aerosols as a function of solar zenith angle. The SBDART is a radiative transfer code based on the discrete-ordinate approach, developed by the University of California, Santa Barbara for the analysis of a wide variety of radiative transfer problems encountered in satellite remote sensing and atmospheric energy budget studies (Ricchiazi et al., 1998) for a plane parallel, vertically inhomogeneous atmosphere. For short wave direct radiative forcing, we used the wavelength range from $0.25 \mu \mathrm{m}$ to $4 \mu \mathrm{m}$ in 38 bands. The estimated fluxes are averaged for the day $(24 \mathrm{~h})$ and aerosol DRF is estimated using Eqs. (1) and (2). The uncertainties in $\mathrm{BC}$ and $F_{\mathrm{BC}}$ estimates (discussed in details in Part 1) are used to get the range through which the estimated model parameters will vary and these are used in the final calculations to get the typical range of variation for the DRF estimated for each season.

Following the above approach we examine the seasonal change in the short wave direct radiative forcing resulting from the corresponding changes in the aerosol properties for the four distinct seasons considered here, namely, winter monsoon season (WMS, month from December to March), inter-monsoon season (IMS, months of April and May), summer monsoon season (SMS, June to September) and post monsoon season (PMS, October and November).

\section{Results and discussion}

We start by summarizing the distinct seasonal features of the optical and microphysical properties of aerosols seen at TVM and described in Part 1. The seasonal mean values of AOD at $500 \mathrm{~nm}$, Angstrom exponent $(\alpha)$, composite aerosol mass concentration $\left(M_{T}\right)$, and $\mathrm{BC}$ mass fraction $\left(F_{\mathrm{BC}}\right)$ are given in Table 1. The main findings of Part 1 are:

- The AOD spectra showed significant seasonal variations, both in magnitude at a given wavelength, as well as in the wavelength dependence.

- The seasonal mean AOD spectra transformed from a steep WMS spectrum (with $\alpha=1.10 \pm 0.03$ ) to a flat one in SMS (with $\alpha=0.32 \pm 0.02$ ). As far as the transition seasons are concerned, IMS showed a much flatter spectrum ( $\alpha=0.85 \pm 0.04)$ compared to PMS $(\alpha=1.20 \pm 0.01)$. Here the values appearing after the \pm symbol are the 
Table 1. Seasonal mean values of (Aerosol Optical Depth) AOD at $500 \mathrm{~nm}$, Angstrom wavelength exponent $\alpha$, mass concentration of composite aerosols $M_{T}$, and mass fraction of $\mathrm{BC}$ to the composite aerosols $\left(F_{\mathrm{BC}}\right)$.

\begin{tabular}{ccccc}
\hline Seasons & AOD at $500 \mathrm{~nm}$ & $\alpha$ & $M_{T}\left(\mu \mathrm{g} \mathrm{m}^{-3}\right)$ & $F_{\mathrm{BC}}(\%)$ \\
\hline WMS & $0.43 \pm 0.01$ & $1.10 \pm 0.03$ & $56.24 \pm 1.6$ & 10.7 \\
IMS & $0.40 \pm 0.03$ & $0.85 \pm 0.04$ & $38.5 \pm 1.2$ & 6.5 \\
SMS & $0.29 \pm 0.03$ & $0.32 \pm 0.02$ & $32.3 \pm 0.8$ & 4.0 \\
PMS & $0.38 \pm 0.04$ & $1.20 \pm 0.01$ & $43.2 \pm 2.0$ & 6.5 \\
\hline
\end{tabular}

standard errors, which are more appropriate statistically when the mean values are compared (Fisher, 1970).

- The seasonal variations in columnar AODs and the Angström coefficients were significantly associated with the variations respectively in the mass concentration of composite aerosols near the surface and its accumulation fraction.

- Despite the fairly large uncertainty $(\sim 20 \%)$ in the BC mass concentration estimated by the aethalometer, the share $\left(F_{\mathrm{BC}}\right)$ of $\mathrm{BC}$ to composite aerosol mass concentration decreased from $11 \%$ during WMS to as low as $4 \%$ during SMS.

Keeping these observations as the constraints, we have developed equivalent seasonal aerosol models, the AODs estimated from which agreed well with the mean AODs from measurements in the region 380 to $1025 \mathrm{~nm}$.

\subsection{Aerosol models}

\subsubsection{Winter Monsoon Season (WMS)}

In view of the continental nature of the airmass and based on the observational features of $\mathrm{AOD}, \alpha$ and $F_{\mathrm{BC}}$, the continental polluted model of Hess et al. (1998) is adapted for this season as the zero order approximation. The major components of this model were taken as water soluble (WSC), insoluble (INS), and BC. Since the study location is a coastal station, it is natural to have an appreciable sea-salt component in the composite aerosols in all seasons with varying abundance, which will be wind speed dependent. Because of the very low surface winds encountered in WMS, we considered only the accumulation mode sea-salt (SSM). In addition, as the 5-day back trajectory analyses (HYSPLIT) showed possibility (though weak) of mineral dust advection from the arid/semi arid regions of north and northwest (see Part 1), transported mineral dust is also added to the above model. The ambient $\mathrm{RH}$ was taken as $50 \%$, in-line with the mean value observed for this season (Fig. 2, Part 1).

The number densities of each of these species are varied; keeping the $\mathrm{BC}$ mass fraction fixed at the observed value
Table 2. The relative contribution of various aerosol species to the composite aerosol optical depth at $500 \mathrm{~nm}$ and relative contribution of various chemical species to the composite aerosol mass (in bracket).

\begin{tabular}{lcccc}
\hline & WMS & IMS & SMS & PMS \\
\hline Water soluble & $45 \%(38.2)$ & $44 \%(28.5)$ & $13 \%(6)$ & $65 \%(54.5)$ \\
Sea-salt & $15 \%(34.6)$ & $27 \%(55.5)$ & $62 \%(87.7)$ & $12 \%(30)$ \\
BC & $37 \%(10.7)$ & $27 \%(6.5)$ & $24 \%(4)$ & $21 \%(6.5)$ \\
Insoluble & $2 \%(14.5)$ & $1 \%(7.5)$ & $-(1)$ & $1 \%(7)$ \\
Transported dust & $1 \%(2)$ & $1 \%(2)$ & $1 \%(1.3)$ & $1 \%(2)$ \\
\hline
\end{tabular}

(10.7\%), until the spectral AODs of the composite aerosols estimated using the model agreed with the observed AOD (with the minimum RMS deviation lower than the mean uncertainty in the measurements). The resulting spectral AOD estimated from the fine-tuned aerosol model (using OPAC) is shown (for the entire wavelength range 0.38 to $4 \mu \mathrm{m}$ ) in Fig. 1a with the dotted line joining the stars, superposed on the average AOD spectra for WMS obtained from the MWR measurements (shown by solid line joining the filled circles). The agreement between the observed and modeled AOD is very good for the common wavelength range and the RMS deviation is only 0.018 . The equivalent aerosol model, which yielded this AOD spectrum, has BC mass fraction at the observed level; aerosols of continental origin (water soluble, $\mathrm{BC}$, and insoluble components together) accounted for $63 \%$ of the composite aerosol mass concentration, while accumulation mode sea-salt accounted for 35\% and transported mineral dust $\sim 2 \%$. The relative contribution of various aerosol species (constituting the model) to the composite aerosol optical depth at $500 \mathrm{~nm}$ and the relative contribution of these species to the composite aerosol mass are listed in Table 2 separately for all the four seasons.

\subsubsection{Inter-monsoon Season (IMS)}

During IMS, the prevailing winds strengthen and start shifting from northeasterlies to northwesterlies with increasing history over oceans. The spectral variation of observed AOD is similar to that of WMS. As such, for this season also, the basic WMS model is selected as the zero-order. The ambient RH was taken as $70 \%$ in the model inline with the mean value observed for this season. The relative abundance of each species is varied as earlier (but keeping $F_{\mathrm{BC}}$ at $6.5 \%$ (in-line with the measurements) so that the AOD spectrum retrieved from the model matched with the mean spectrum from measurements, with an RMS deviation of 0.019. The AOD spectrum estimated from the model is shown in Fig. 1b as dotted line joining stars and the AOD measured using MWR is shown as continuous line joining filled circle with vertical bars. The basic difference of the "IMS model" from the "WMS model" is the significant reduction in the share 


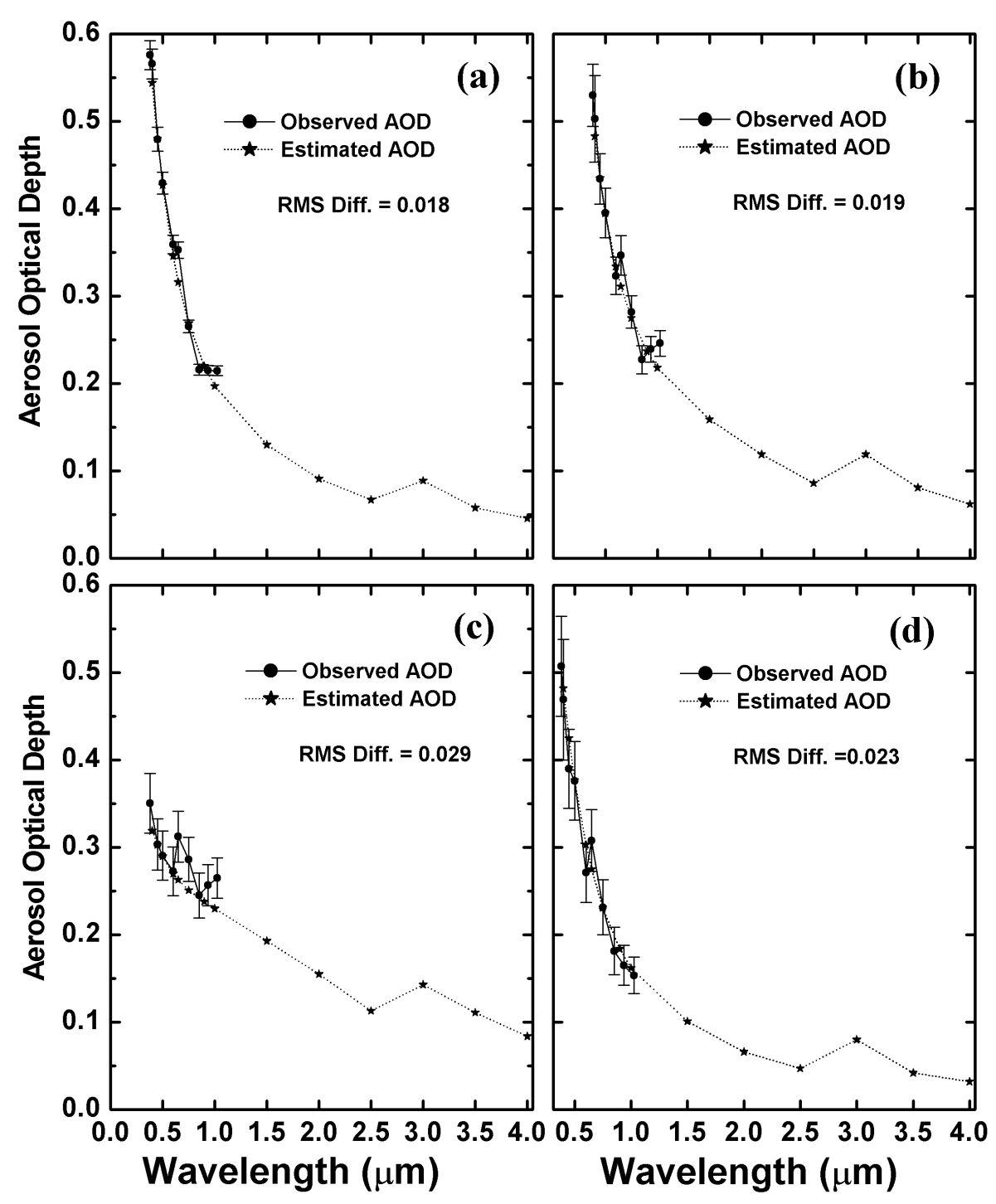

Fig. 1. Comparison of estimated (dotted line with star symbol) and measured (continuous line joining filled circle with vertical bars) aerosol spectral optical depths for (a) Winter Monsoon Season (December through March), (b) Inter-monsoon season (April and May), (c) Summer Monsoon Season (June through September) and (d) Post Monsoon Season (October and November). The vertical bars represent the standard error.

of continental aerosols to $43 \%$ (from 63\%) and the large increase in sea-salt, which now accounts for $55 \%$.

\subsubsection{Summer Monsoon Season (SMS)}

During the SMS, prevailing winds are almost entirely northwesterlies, arriving from the ocean after a considerable seatravel, constituting a marine airmass. Due to the higher wind speeds encountered in this season and proximity of the station to the coast, both accumulation and coarse mode of the sea salt are important in this season. Nevertheless, there still will be a significant continental component and some impact of continental activities. Hence, we adopted a marine polluted model as the zero order for the SMS and trans- ported mineral dust is added following the earlier consideration. The species concentrations are adjusted; keeping the $\mathrm{BC}$ mass fraction constrained to $4 \%$ (in line with the measurement) to match the spectral AODs. Here the ambient RH was taken as $70 \%$. The spectral AOD estimated from the model and measured using MWR is shown in Fig. 1c. Here the match was not as excellent as the previous two seasons and RMS deviation was 0.029 ; yet it was within the observational errors, which are also higher in this season. Here a short account of a small spike occurring in the measured AOD spectrum at $650 \mathrm{~nm}$ is warranted, as the deviation from the model estimate is most around this. We have checked this for any instrument artifact and found nil. This pattern of the AOD spectrum was frequently observed especially during 


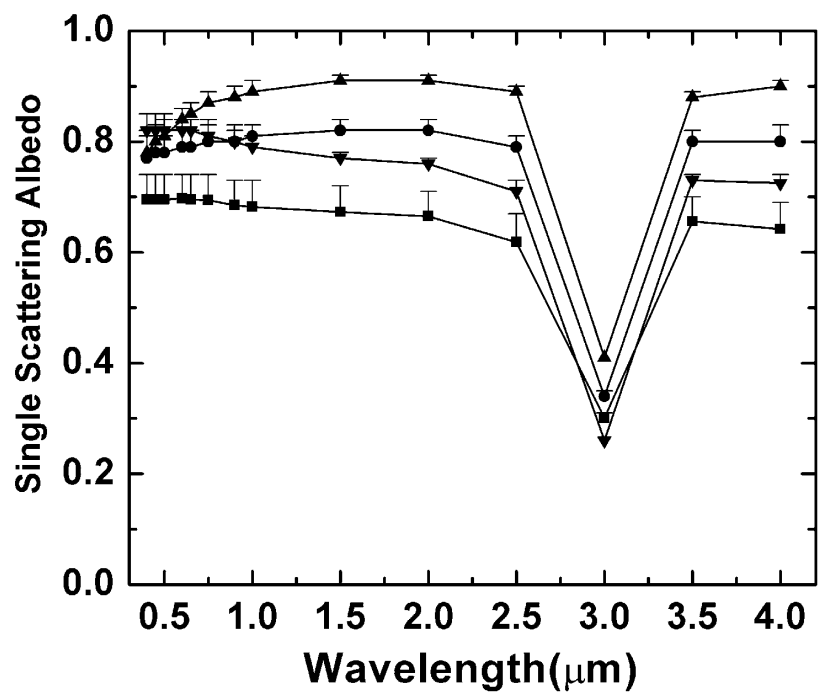

Fig. 2. Spectral variation of single scattering albedo estimated for different seasons. The vertical bars shows the range of variation caused by the uncertainty in aethalometer estimated BC.

SMS season and with other instruments also (like the microtops, in which this occurs at $675 \mathrm{~nm}$ ). This type of AOD spectra were also seen in cruises around the coastal waters of the Arabian Sea. In other seasons, this peak becomes inconspicuous, and hardly visible during WMS. We attribute this to be contributed by the ever-present sea salt component (in the coarse mode). The columnar size distribution inverted from the AOD spectra also show a mode at $\sim 1 \mu \mathrm{m}$, which is also seen in the near-surface aerosol size distributions (Pillai and Moorthy, 2001). This is the season when the wind speeds are the highest of the year. At near-surface, the coarse mode accounts for more than $50 \%$ of the total aerosol mass during SMS. The reduced vertical mixing in this season (due to cloudy conditions and low air temperature) is also conducive for causing a vertical inhomogenity in aerosol size spectra, with the coarse particles being confined to the lower troposphere (Pillai and Moorthy, 2004). Moreover, the washout by the monsoon rains affect particles of different sizes differently (Saha and Moorthy, 2004). During SMS, the modeled aerosol composition changes significantly from an anthropogenically dominated one to natural dominated one; the sea-salt contributing to as much as $88 \%$ to the composite mass, while the share of continental aerosols comes down to as low as $11 \%$.

\subsubsection{Post Monsoon Season (PMS)}

During the post monsoon season, winds are weak and are again in a transition from marine to continental; but the rainfall is significant. The spectral variation of AOD observed during this season is similar to that of WMS but with lower AODs at longer wavelength, implying a reduction in the concentration of coarse aerosols, probably sea-salt, because of low wind speeds. The equivalent aerosol model for this season is constructed as discussed earlier with $F_{\mathrm{BC}}$ constrained at $6.5 \%$ and $\mathrm{RH}$ at $70 \%$ (in-line with the measurement). The spectral AOD estimated using this model is compared with mean observed AOD spectrum in Fig. 1d. The agreement is good and RMS deviation is 0.023 . Interestingly, the share of continental aerosols recovers to $68 \%$ by now and that of the sea salt comes down to $30 \%$.

The contributions of each of the species considered in these models to the composite aerosol optical depth at $500 \mathrm{~nm}$ for the different seasons are also given in Table 2 . It is interesting to note that $\mathrm{BC}$ is the second largest contributor to the composite AOD in all the seasons except in IMS; when sea-salt also contributes nearly as much. It is very interesting to see that the share of $\mathrm{BC}$ to composite AOD is the lowest in PMS, even though BC is lowest in SMS. Despite, even at its lowest value, its share is nearly twice the share reported by Satheesh et al. (1999), for northern tropical Indian Ocean thereby showing the significance of high BC share over the landmass. Similarly, sea salt, which contributes only 12 to $15 \%$ to the composite AOD during WMS and PMS, contributes as much as $62 \%$ in SMS.

\subsection{Estimated optical properties}

Using the seasonal aerosol models developed above, the single scattering albedo $(\omega)$ as a function of $\lambda$ and phase function $P(\theta)$ (as a function of scattering angle $\theta$ ) were estimated. The spectral variation of $\omega$ thus obtained is shown in Fig. 2 for the spectral range from 0.3 to $4 \mu \mathrm{m}$ separately for the four seasons considered. The striking feature is the very low value of $\omega$ (0.7 to 0.74 ) in WMS; which is far separated from the $\omega$ values for the other seasons. During the other three seasons, values of $\omega$ are more or less comparable $(\sim 0.8)$ and are much higher than that for WMS. However, it is to be noted here that these values of $\omega$ are the lower estimates, if we consider uncertainties in the aethalometer estimates outlined in the Part 1 of this paper. Accordingly, if we consider the aethalometer overestimated the $\mathrm{BC}$ concentrations up to $\sim 20 \%$, then the $\omega$ values could be higher than the values mentioned above. We have repeated the entire procedure described above with a $20 \%$ reduction in $\mathrm{BC}$ mass estimates and the SSA are re-estimated, and are shown by the vertical bars over the points; which shows the range over which the estimated values of $\omega$ might vary due to the uncertainty in the aethalometer measurements. For the wavelength of $500 \mathrm{~nm}$, the values then ranges between 0.70 and 0.74 for WMS, 0.78 and 0.81 for IMS, 0.81 and 0.84 for SMS and 0.82 and 0.85 for PMS. Even after considering these ranges of variations of $\omega$, it is clear that the values for SMS and PMS are significantly higher than the values of WMS and IMS thereby implying a seasonal change in the absorbing nature of the aerosols. The distinct wavelength dependence of $\omega$ in SMS (with $\omega$ increasing at longer wavelengths) is apparently caused by the increased abundance of 
sea-salt aerosols. Because of its large size, sea-salt aerosols efficiently scatter at longer wavelengths than at shorter wavelengths. During WMS and IMS, $\omega$ weakly decreases towards longer wavelengths.

At this juncture we compare the values $\omega$ obtained from our study with those reported from different regions of India and adjoining oceans by different investigators. For WMS, $\omega$ at TVM is lower than the values reported for Arabian Sea and Indian Ocean by several investigators (Podgorney et al., 2000; Lelieveld et al., 2001) and is comparable to that reported for an urban location, Bangalore (Babu et al., 2002) for PMS, despite the study location being far less urbanized and practically unindustrialized. On the other hand the summer values at TVM are quite comparable with the winter values reported for southern Indian Ocean during the INDOEX (Ramanathan et al., 2001). Examining other continental and urban locations elsewhere in Asia, we observe that such large seasonal variations in $\omega$ with very low value in winter (similar to that seen in our study) have been reported. For example, the seasonal mean value of $\omega$ at $500 \mathrm{~nm}$ reported by Nishizawa et al. (2004) over Tsukuba (an urban location close to Tokyo), Japan were 0.69 in winter, 0.79 in spring, 0.87 in summer, and 0.77 in autumn and an annual mean value of 0.75. Similarly, Hayasaka et al. (1992) reported 0.69 in winter, 0.80 in spring, 0.93 in summer and 0.75 in autumn, for the seasonal mean single scattering albedo at $632.8 \mathrm{~nm}$ for Sendai, another coastal, urban centre and port in Japan. Noting that the winter season in the above studies is same as our WMS and the summer is nearly same as our SMS, our values are comparable to these. However, the values of $\omega$ obtained in the present study is lower than those reported over several major biomass-burning regions around the world (Reid et al., 2005). The phase functions (shown in Fig. 3) show similar pattern in all seasons except for SMS. In SMS, the significant amount of coarse mode particles causes $P(\theta)$ to deviate in its angular pattern.

\subsection{Direct, short-wave radiative forcing}

Using the above seasonal aerosol models and the estimated optical properties, we estimated the direct short wave radiative forcing for the wavelength range 0.25 to $4.0 \mu \mathrm{m}$. The observed values of aerosol spectral AODs, and $\alpha$, along with estimated values of $\omega$ and $P(\theta)$ for different seasons are incorporated into the SBDART and the diurnally averaged, shortwave, clear sky aerosol DRF at the surface and top of the atmosphere are estimated following Eq. (1). Here we have considered only the seasonal mean values of $\mathrm{AOD}, \alpha, \omega$ and $P(\theta)$ and neglected diurnal variations and day to day variations with in the season. Since the observation location is a vegetated coastal station with the vegetation (mainly trees) showing only very weak seasonal changes in the canopy cover, the surface reflectance is taken as $50 \%$ vegetation and $50 \%$ ocean. The surface reflectance values used in the present study at typical wavelengths are given in Table 3 .

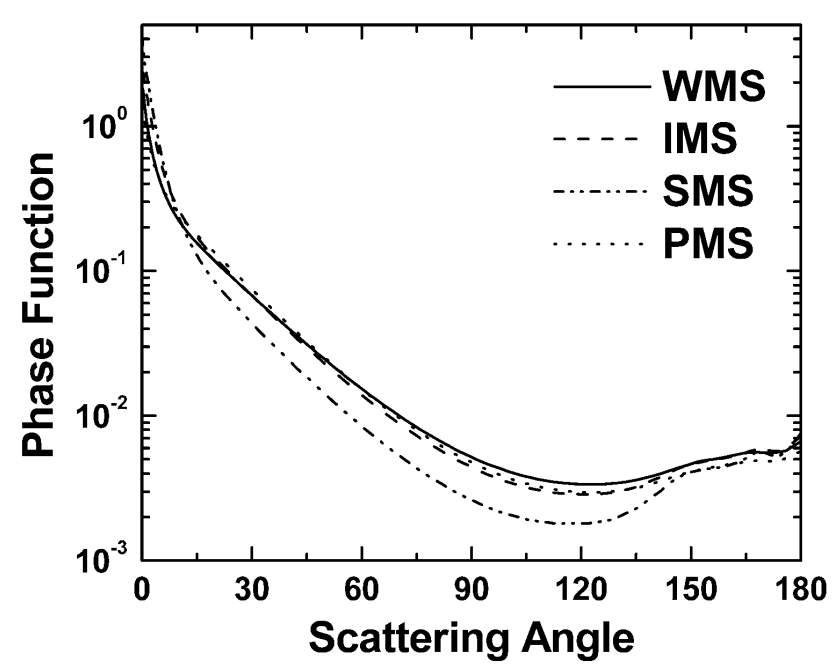

Fig. 3. Phase function of the modeled composite aerosol system for different seasons. Note the effect of increased coarse aerosols on the phase function in the summer monsoon season.

The components of the diurnally averaged, direct, short wave radiative forcing for clear sky conditions are shown in Fig. 4 for different seasons, with the panels from bottom to top representing TOA, surface and atmospheric forcing respectively. The shaded portion in Fig. 4 represents the values correspond to the upper limits of the radiative forcing estimates with the lowest value of $\omega$. If we consider the overestimation of $\mathrm{BC}$ and consequent underestimation of $\omega$, the magnitude of the forcing decreases and is represented by the hashed portion in Fig. 4 . In Table 4 we give the range of values through which the forcing components would thus vary. In same table aerosol radiative forcing estimates made at other locations in India are also given for comparison. It shows the large seasonal changes in the aerosol radiative forcing and its spatial heterogeneity in a given season. The most significant observations are

1. The diurnally averaged TOA forcing $\left(\Delta F_{\mathrm{TOA}}\right)$ is significantly positive (ranges between +1.83 and $+4 \mathrm{~W} \mathrm{~m}^{-2}$ ) during WMS, and negative during SMS and PMS (ranges between -1.4 and -2.6 and -1.5 and $-2.8 \mathrm{~W} \mathrm{~m}^{-2}$ ). During IMS, the TOA forcing values ranges between +0.28 and $-1.4 \mathrm{~W} \mathrm{~m}^{-2}$. These seasonal changes are attributed mainly to the decrease in $F_{\mathrm{BC}}$. The reversal of the sign (from negative to positive) of the $\Delta F_{\text {TOA }}$ for WMS implies that the presence of the "winter aerosols" in the atmosphere leads to a further reduction in the outgoing radiation due to increased absorption.

2. The diurnally averaged surface forcing is as large as $-50 \mathrm{~W} \mathrm{~m}^{-2}$ in WMS and gradually decreases in magnitude to reach $-30 \mathrm{~W} \mathrm{~m}^{-2}$ by SMS, and increases in PMS. 
Table 3. The surface reflectances at typical wavelengths.

\begin{tabular}{lcccccccc}
\hline$\lambda(\mathrm{nm})$ & 300 & 400 & 500 & 600 & 700 & 800 & 900 & 1000 \\
\hline $\begin{array}{l}\text { Surface } \\
\text { reflectance }\end{array}$ & 0.021 & 0.051 & 0.078 & 0.070 & 0.173 & 0.262 & 0.266 & 0.268 \\
\hline
\end{tabular}

Table 4. Comparison of the radiative forcing (in $\mathrm{W} \mathrm{m}^{-2}$ ) estimates over TVM with other similar estimates made elsewhere.

\begin{tabular}{lccccl}
\hline Area/Location & Period & TOA & Surface & Atmosphere & Reference \\
\hline TVM & Dec-March & +4.1 to +1.8 & -48.9 to -44.8 & +52.9 to +46.6 & Present study \\
TVM & April-May & +0.3 to -1.4 & -37.4 to -34.2 & +37.6 to +32.8 & Present study \\
TVM & June-Sep & -1.4 to -2.6 & -26.9 to -24.4 & +25.5 to +21.8 & Present study \\
TVM & Oct-Nov & -1.5 to -2.8 & -30.2 to -27.8 & +28.7 to +25.0 & Present study \\
Bangalore & Nov & +5 & -23 & +28 & Babu et al. (2002) \\
Pune & Nov-April & 0 & -33 & +33 & Pandithurai et al. (2004) \\
Central India & Feb & +0.7 to -11 & -15 to -40 & & Ganguly et al. (2005) \\
Kanpur & Dec & $+9 \pm 3$ & $-62 \pm 23$ & & Tripathi et al. (2005) \\
Nainital & Dec & +0.7 & -4.2 & +4.9 & Pant et al. (2006) \\
Arabian Sea & March-April & -11.6 to -12.3 & -25.7 to -28.3 & +13.4 to +16.7 & Moorthy et al. (2005) \\
Bay of Bengal & March & -4 & -27 & +23 & Satheesh (2002) \\
Indian Ocean & Feb-March & -10 & -29 & +19 & Satheesh et al. (2002) \\
\hline
\end{tabular}

3. Atmospheric forcing is highest in WMS $\left(55 \mathrm{~W} \mathrm{~m}^{-2}\right)$ and lowest in SMS $\left(25 \mathrm{~W} \mathrm{~m}^{-2}\right.$, less than half the winter forcing).

The magnitude of the aerosol radiative forcing is highly dependent not only on the type of the aerosols, but also on its column abundance. Consequently, it is a strong function of the AOD. The rate at which the atmosphere is forced per unit optical depth is known as the forcing efficiency. It is obtained by dividing $\Delta F$ by AOD at $500 \mathrm{~nm}$, and is a better indicator of the forcing potential of a given type of composite aerosol particles. The forcing efficiency estimated at TOA, surface and in the atmosphere for different seasons are given in Table 5. For INDOEX-1998 data, Podgorny et al. (2000) reported aerosol forcing efficiency values of $-82 \mathrm{~W} \mathrm{~m}^{-2} \tau^{-1}$ (where $\tau$ stands for AOD at $500 \mathrm{~nm}$ ) for the surface, $-20 \mathrm{~W} \mathrm{~m}^{-2} \tau^{-1}$ for the TOA, and $62 \mathrm{~W} \mathrm{~m}^{-2} \tau^{-1}$ for atmosphere over Indian Ocean, while Satheesh and Ramanathan (2000) reported the forcing efficiency at the surface to be in the range -70 to $-75 \mathrm{~W} \mathrm{~m}^{-2} \tau^{-1}$ and at the TOA to be -22 to $-25 \mathrm{~W} \mathrm{~m}^{-2} \tau^{-1}$ over same region and season, but for 1999. Based on Arabian Sea Monsoon Experiment (ARMEX), Moorthy et al. (2005) reported that the forcing efficiencies over Arabian Sea during the inter-monsoon season are $-61 \mathrm{~W} \mathrm{~m}^{-2} \tau^{-1}$ for the surface, $-27 \mathrm{~W} \mathrm{~m}^{-2} \tau^{-1}$ for TOA and $+34 \mathrm{~W} \mathrm{~m}^{-2} \tau^{-1}$ for the atmosphere. However, based on the same experiment but during summer monsoon season (July-August) Vinoj and Satheesh (2003) reported short wave aerosol direct forcing efficiencies of
$-37.5 \mathrm{~W} \mathrm{~m}^{-2} \tau^{-1}$ for the TOA, $-43.75 \mathrm{~W} \mathrm{~m}^{-2} \tau^{-1}$ at the surface and $+6.25 \mathrm{~W} \mathrm{~m}^{-2} \tau^{-1}$ for the atmosphere. Viewed in the light of the above, the forcing efficiency values resulting in our study are much higher for any corresponding season. This might be mainly due to the facts that (i) Unlike with the other works, our estimation is over a landmass where the $\mathrm{BC}$ mass fraction is higher (in any season as compared to its value over the ocean for the same season) and (ii) the surface albedo in our study is much higher than that of ocean.

The atmospheric forcing component of the aerosol radiative forcing is the most important value for climate scientists for assessing the probable impact on regional climate (Moorthy et al., 2005). Climate impact is usually assessed by estimating the heating rate given by,

$$
\frac{\partial T}{\partial t}=\frac{g}{c_{p}} \frac{\left(\Delta F_{A}\right)}{\Delta P}
$$

where $\frac{\partial T}{\partial t}$ is the heating rate $\left(\mathrm{K}\right.$ day $\left.^{-1}\right), g$ is the acceleration due to gravity, $C_{p}$ the specific heat capacity of air at constant pressure $\left(\sim 1006 \mathrm{~J} \mathrm{~kg}^{-1} \mathrm{~K}^{-1}\right)$ and $P$ is the atmospheric pressure, respectively. Using the above equation, we computed (taking $\Delta P$ as $300 \mathrm{hPa}$ ) the range of heating rates for each season and these are given in the last column of Table 5. In line with the seasonal changes in atmospheric forcing the diurnally averaged heating rates decreased from as high as 1.3 to $1.5 \mathrm{~K} \mathrm{day}^{-1}$ in WMS to 0.6 to $0.7 \mathrm{~K} \mathrm{day}^{-1}$ in SMS. While $300 \mathrm{hPa}$ for $\Delta P$ (meaning that the aerosol layer is concentrated in the first $3 \mathrm{~km}$ above ground) is valid for TVM for 
Table 5. The range of values for forcing efficiency obtained for different seasons.

\begin{tabular}{ccccc}
\hline \multirow{2}{*}{ Seasons } & TOA & Sorcing Efficiency (in $\mathrm{W} \mathrm{m}^{-2} \tau^{-1}$ ) & Heating rate $\left(\mathrm{K} \mathrm{day}^{-1}\right.$ ) \\
& The & Atmosphere & Her \\
\hline WMS & +9.5 to +4.2 & -113.9 to -104.4 & +123.5 to +108.6 & 1.51 to 1.33 \\
IMS & +0.7 to -3.5 & -94.6 to -86.6 & +95.3 to +83.0 & 1.08 to 0.93 \\
SMS & -4.8 to -8.9 & -92.5 to -83.8 & +87.7 to +74.9 & 0.73 to 0.62 \\
PMS & -4.0 to -7.4 & -80.4 to -73.9 & +76.4 to +66.5 & 0.82 to 0.71 \\
\hline
\end{tabular}

WMS, (based on LIDAR measurements, e.g., Parameswaran et al., 1995; Muller et al., 2001), during SMS, it reduces significantly to $\sim 100$ to $150 \mathrm{hPa}$ (Parameswaran et al., 1995). In such cases the heating rate would increase from the values given in Table 5. As such, we have carried out a sensitivity study to assess the effect of possible variations in $\Delta P$ as a function of season. If we use a value of $100 \mathrm{hPa}$ (the lowest value, reported for SMS) for $\Delta P$ (aerosol is concentrated in the layer from surface to $1 \mathrm{~km}$ ), then heating rate increases to 4.4 $\mathrm{K} \mathrm{day}^{-1}$ in WMS and 2.1 $\mathrm{K} \mathrm{day}^{-1}$ in SMS. However, typically $\Delta P$ will lie between these extremes Thus, the realistic value of lower atmospheric heating rate may deviate as much as 30 to $50 \%$ depending on aerosol mixing height compared to that estimated using a mean $\Delta P$ of $300 \mathrm{hPa}$. Based on the measurement over Arabian Sea, Moorthy et al. (2005) reported a heating rate value of $0.42 \mathrm{~K} \mathrm{day}^{-1}$ for the first $3 \mathrm{~km}$ layer during IMS, which is very much less than the values reported in the present study, because of the low BC mass fraction $(\sim 2.2 \%)$ over ocean and the low surface albedo of ocean compared to the land. Here it is to be emphasized that this heating rate is only a theoretical, static, 1-D estimate and is due to absorption of short wave flux only. More realistic estimates should consider the long wave part as well as boundary layer processes.

The large TOA warming and low single scattering albedo values, seen in this study, are not unique features of the locality; rather they appear to be characteristic to the region. Based on extensive measurements of aerosol single scattering albedo (SSA) over various locations of the central and northern Indian region during February 2004. Ganguly et al. (2005) have reported SSA as low as 0.75. Based on this, they estimated diurnally averaged value of direct SW radiative forcing as high as $-40 \mathrm{~W} \mathrm{~m}^{-2}$ at the surface and +0.7 at the TOA (strong heating similar to what we observe here). During a comprehensive aerosol field campaign in December 2004, extensive measurements of aerosol black carbon were made at Kanpur, an urban continental location in northern India by Tripathi et al. (2005). They reported BC concentrations as high as 6 to $20 \mu \mathrm{g} \mathrm{m}^{-3}$ and mass fraction (close to $\sim 10 \%$ ) resulting in a very low single scattering albedo (0.76). The estimated surface forcing was as high as $-62 \mathrm{~W} \mathrm{~m}^{-2}$ and top of the atmosphere (TOA) forcing is $+9 \mathrm{~W} \mathrm{~m}^{-2}$ (strong heating similar to our case), which means
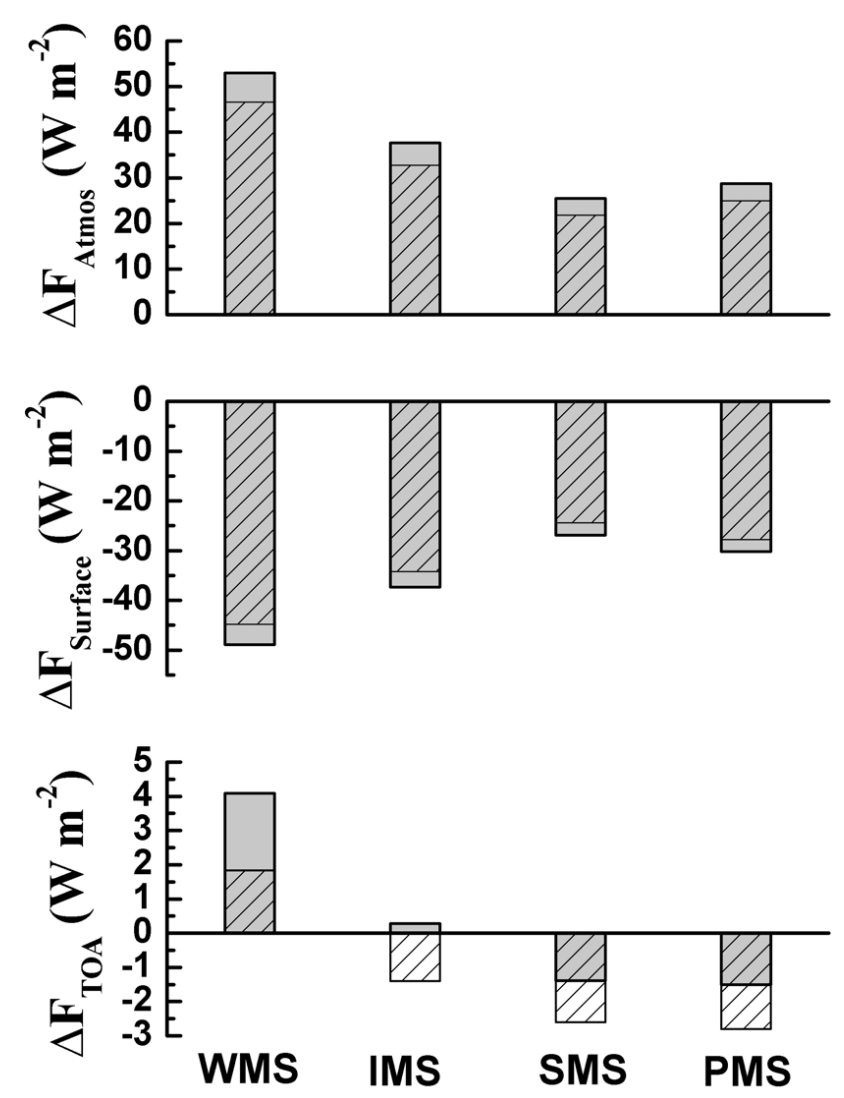

Fig. 4. Clear sky aerosol radiative forcing at TOA (bottom), surface (middle) and in the atmosphere (top). Here the shaded portion corresponds to the radiative forcing estimations without considering the uncertainty in aethalometer measurements and the hashed portion corresponds to the estimations after considering the $20 \%$ over estimation by aethalometer.

the atmospheric absorption is $+71 \mathrm{~W} \mathrm{~m}^{-2}$. For an urban location Bangalore in south India, Babu et al. (2002) have estimated SSA as low as 0.76 and consequent strong TOA warming $\left(+5 \mathrm{~W} \mathrm{~m}^{-2}\right)$. All these indicate persistent high atmospheric forcing in winter over several Indian regions. The significance of our observation is the large increase in the SSA at Trivandrum as the season changes from winter to summer. 


\section{Conclusions}

Seasonal changes in the aerosol characteristics, deduced from collocated and long-term measurements at Trivandrum, are used to develop seasonal aerosols models and the impact on the direct short wave radiative forcing has been made. The important findings are

- The modeled composite aerosols show a large domination of anthropogenic fine mode aerosols during WMS contributing to as much $64 \%$ to the total aerosol burden, while sea salt (accumulation mode) contributed only $\sim 35 \%$. In contrast, during SMS, sea-salt (coarse and accumulation together) accounted for $\sim 88 \%$ of the composite aerosols. Thus the aerosols change from anthropogenic domination in WMS to natural domination in SMS.

- Consequently, the inferred SSA at $500 \mathrm{~nm}$ increased from its least value $(\sim 0.70$ to 0.74$)$ during WMS to $\sim 0.81$ to 0.84 during SMS. This large change in $\omega$ leads to seasonal changes in atmospheric forcing.

- The estimated clear-sky radiative forcing showed that, the TOA forcing is significantly positive during WMS, but changes to the normally expected negative values during SMS and PMS. The magnitude of the surface forcing decreases from WMS to SMS and increases for PMS so that atmospheric forcing is highest in WMS and decreases to the lowest value in SMS, implying a large seasonal heterogeneity.

- The estimated heating rates decrease from as high as $1.5 \mathrm{~K} \mathrm{day}^{-1}$ in WMS to $\sim 0.7 \mathrm{~K} \mathrm{day}^{-1}$ in SMS for a nominal $\Delta P$ of $300 \mathrm{hPa}$. However, under realistic conditions, these values could be differing by 30 to $50 \%$, particularly in SMS, when the aerosols are confined closer to the surface. These observations are important in modeling aerosol climate impacts.

Acknowledgements. This study was carried out under the Aerosol Radiative Forcing over India (ARFI) project of ISRO-Geosphere Biosphere Program (ISRO-GBP). We thank the anonymous reviewers for several useful comments.

Topical Editor F. D'Andrea thanks B. V. KrishnaMurthy and another anonymous referee for their help in evaluating this paper.

\section{References}

Ackerman, A. S., Toon, O. B., Stevens, D. E., Heymsfield, A. J., Ramanathan, V., and Welton, E. J.: Reduction of tropical cloudiness by soot, Science, 288, 1042-1047, 2000.

Andreae, M. O., Jones, C. D., and Cox, P. M.: Strong present-day aerosol cooling implies a hot future, Nature, 435, 1187-1190, doi:10.1038/nature03671, 2005.

Babu, S. S., Satheesh, S. K., and Moorthy, K. K.: Aerosol radiative forcing due to enhanced black carbon at an urban site in India,
Geophys. Res. Lett., 29(18), 1880, doi:10.1029/2002GL015826, 2002.

Bond, T. C. and Bergstrom, R. W.: Light absorption by carbonaceous particles: An investigative review, Aerosol Sci. Technol., 40, 27-67, 2006.

Boucher, O. and Haywood, J.: On summing the components of radiative forcing of climate change, Clim. Dynam., 18, 297-302, 2001.

Chandra, S., Satheesh, S. K., and Srinivasan, J.: Can the state of mixing of black carbon aerosols explain the mystery of 'excess' atmospheric absorption?, Geophys. Res. Lett., 31, 2004, doi:10.1029/2004GL020662, 2004.

Charlson, R. J., Schwartz, S. E., Hales, J. M., Cess, R. D., Coakley, J. A., Hansen, J. E., and Hofmann, D. J.: Climate forcing by anthropogenic aerosols, Science, 255, 423-430, 1992.

Chin, M., Ginoux, P., Kinne, S., et al.: Tropospheric aerosol optical thickness from the GOCART model and comparisons with satellite and Sunphotometer measurements, J. Atmos. Sci., 59, 461-483, 2002.

Conant, W. C., Seinfield, J. H., Wang, J., Carmichael, G. R., Tang, Y., Uno, I., Flatau, P. J., Markowicz, K. M., and Quinn, P. K.: A model for the radiative forcing during ACE-Asia derived from CIRPAS Twin Otter and R/V Ronald H. Brown data and comparison with observations, J. Geophys. Res., 108(D23), 8661, doi:10.1029/2002JD003260, 2003.

Fisher, R. A.: Statistical methods for research workers, Oliver and Boyd, Edinburgh, 362pp, 1970.

Ganguly, D., Gadhavi, H., Jayaraman, A., Rajesh, T. A., Misra, A.: Single scattering albedo of aerosols over the central India: Implications for the regional aerosol radiative forcing, Geophys. Res. Lett., 32, L18803, doi:10.1029/2005GL023903, 2005.

Ganguly, D., Jayaraman, A., and Gadhavi, H.: Physical and optical properties of aerosols over an urban location in western India: Seasonal variabilities, J. Geophys. Res., 111, D24206, doi:10.1029/2006JD007392, 2006.

Girolamo, L., Bond, T. C., Bramer, D., Diner, D. J., Fettinger, F., Kahn, R. A., Martonchik, J. V., Ramana, M. V., Ramanathan, V., and Rasch, P. J.: Analysis of multiangle imaging spectroradiometer (MISR) aerosol optical depths over greater India during winter 2001-2004, Geophys. Res. Lett., 31, L23115, doi:10.1029/2004GL021273, 2004

Hansen, J. E., Sato, M., and Ruedy, R.: Radiative forcing and climate response, J. Geophys. Res., 102, 6831-6864, 1997.

Hayasaka, T., Nakajima, T., Ohta, S., and Tanaka, M.: Optical and chemical properties of urban aerosols in Sendai and Sapporo, Japan, Atmos. Environ., 26A, 2055-2062, 1992.

Haywood, J. M., Roberts, D. L., Slingo, A., Edwards, J. M., and Shine, K. P.: General circulation model calculations of the direct radiative forcing by anthropogenic sulphate and fossil- fuel soot aerosol, J. Climate, 10, 1562-1577, 1997.

Haywood, J. M. and Shine, K. P.: Multi-spectral calculations of the direct radiative forcing of tropospheric sulphate and soot aerosols using a column model, Q. J. Roy. Meteor. Soc., 123, 1907-1930, 1997.

Haywood, J. M. and Ramaswamy, V.: Global sensitivity studies of the direct radiative forcing due to anthropogenic sulfate and black carbon aerosols, J. Geophys. Res., 103, 6043-6058, 1998.

Hess, M., Koepke, P., and Schultz, I.: Optical properties of aerosols and clouds: The software package OPAC, B. Am. Meteorol. 
Soc., 79, 831-844, 1998.

Huebert, B. J., Bates, T., Russell, P. B., Shi, G., Kim, Y. J., Kawamura, K., Carmichael, G., and Nakajima, T.: An overview of ACE-Asia: Strategies for quantifying the relationships between Asian aerosols and their climatic impacts, J. Geophys. Res., 108, 8633, doi:10.1029/2003JD003550, 2003.

Intergovernmental Panel on Climate Change (IPCC), Climate Change 2001: The Scientific Basis, Contribution of Working Group I to the Third assessment report of the Intergovernmental Panel on Climate Change, edited by: Houghton, J. T., Ding, Y., Griggs, D. J., Noguer, M., vander Linden, P. J., Dai, X., Maskell, K., and Johoson, C. A., Cambridge University Press, Cambridge, 81 pp., 2001.

Jacobson, M. Z.: A physically based treatment of elemental carbon optics: Implications for global direct forcing of aerosols, Geophys. Res. Lett., 27, 217-220, 2000.

Kaufman, Y. J., Hobbs, P. V., Kirchhoff, V. W. J. H., Artaxo, P., Remer, L. A., Holben, B. N., King, M. D., Ward, D. E., Prins, E. M., Longo, K. M., Mattos, L. F., Nobre, C. A., Spinhirne, J. D., Ji, Q., Thompson, A. M., Gleason, J. F., Christopher, S. A., and Tsay, S. C.: Smoke, Clouds, and Radiation-Brazil (SCAR_B) experiment, J. Geophys. Res., 103, 31 783-31 808, 1998.

Kaufman, Y. J., Tanré, D., and Boucher, O.: A satellite view of aerosols in the climate system, Nature, 419, 215-223, 2002.

Keil, A. and Haywood, J. M.: Solar radiative forcing by biomass burning aerosol particles during SAFARI 2000: A case study based on measured aerosol and cloud properties. J. Geophys. Res., 108(D13), 8467, doi:10.1029/2002JD002315, 2003.

Kinne, S., Lohmann, U., Feichter, J., et al.: Monthly averages of aerosol properties: A global comparison among models, satellite data, and AERONET ground data, J. Geophys. Res., 108(D20), 4634, doi:10.1029/2001JD001253, 2003.

Koepke, P., Hess, M., Schult, I., and Shettle, E. P.: Global aerosol data set, MPI Meteorology Hamburg Report No, 243, 44 pp, 1997.

Lelieveld, J., Crutzen, P. J., Ramanathan, V., et al.: The Indian Ocean Experiment: Widespread air pollution from South and Southeast Asia, Science, 291, 1031-1036, 2001.

Markowicz, K. M., Flatau, P. J., Quinn, P. K., Carrico, C. M., Flautau, M. K., Vogelmann, A. M., Bates, D., Liu, M., and Rood, M. J.: Influence of relative humidity on aerosol radiative forcing: An ACE-Asia experiment perspective, J. Geophys. Res., 108(D23), 8662, doi:10.1029/2002JD003066, 2003.

Moorthy, K. K., Babu, S. S., and Satheesh, S. K.: Aerosol characteristics and radiative impacts over the Arabian Sea during intermonsoon season: Results from ARMEX field campaign, J. Atmos. Sci., 62, 192-206, 2005.

Muller, D., Franke, K., Wagner, F., Althausen, D., Ansmann, A., and Heintzenberg, J.: Vertical profiling of optical and physical particle properties over the tropical Indian Ocean with six wavelength lidar, 1, Seasonal cycle, J. Geophys. Res., 106, 28 567$28575,2001$.

Niranjan, K., Rao, B. M., Brahmanandam, P. S., Madhavan, B. L., Sreekanth, V., and Moorthy, K. K.: Spatial characteristics of aerosol properties over the northeastern parts of peninsular India, Ann. Geophys., 23, 3219-3227, 2005, http://www.ann-geophys.net/23/3219/2005/.

Nishizawa, T., Shoji, A., Uchiyama, A., and Yamazaki, A.: Seasonal variation of aerosol direct radiative forcing and optical properties estimated from ground based solar radiation measurements, J. Atmos. Sci., 61, 57-72, 2004.

Pandithurai, G., Pinker, R. T., Takemura, T., Devara, P. C. S.: Aerosol radiative forcing over a tropical urban site in India, Geophys. Res. Lett., 31, L12107, doi:10.1029/2004GL019702, 2004.

Parameswaran, K., Vijayakumar, G., Murthy, B. V. K., and Moorthy, K. K.: Effect of wind speed on mixing region aerosol concentrations at a tropical coastal station, J. Appl. Meteorol., 34 1392-1397, 1995.

Penner, J. E., Chuang, C. C., and Grant, K.: Climate forcing by carbonaceous and sulphate aerosols, Clim. Dynam., 14, 839-851, 1998.

Penner, J. E., Zhang, S. V., Chin, M., et al.: A comparison of model and satellite derived aerosol optical depth and reflectivity, J. Atmos. Sci., 59, 441-460, 2002.

Pillai, P. S. and Moorthy, K. K.: Size distribution of near surface aerosols and its relation to the columnar Aerosol Optical Depths - Response to airmass types, Ann. Geophys., 22, 3347-3351, 2004, http://www.ann-geophys.net/22/3347/2004/.

Pilnis, C., Pandis, S. N., and Seinfield, J. H.: Sensitivity of direct climate forcing by atmospheric aerosols to aerosol size composition, J. Geophys. Res., 100, 18 739-18 754, 1995.

Podgorney, I. A. and Ramanathan, V.: A modeling study of the direct effect of aerosols over the tropical Indian Ocean, J. Geophys. Res., 106, 24 097-24 105, 2001.

Podgorny, I. A., Conant, W. C., Ramanathan, V., and Satheesh, S. K.: Aerosol modulation of atmospheric and surface solar heating rates over the Tropical Indian Ocean, Tellus, 53B, 947-958, 2000.

Reid, J. S., Eck, T. F., Christopher, S. A., Koppmann, R., Dubovik, O., Eleuterio, D. P., Holben, B. N., Reid, E. A., and Zhang, J.: A review of biomass burning emissions part III: intensive optical properties of biomass burning particles, Atmos. Chem. Phys., 5, 827-849, 2005,

http://www.atmos-chem-phys.net/5/827/2005/.

Ricchiazzi, P., Yang, S., Gautier, C., and Sowle, D.: SBDART: A research and teaching tool for plane-parallel radiative transfer in the Earth's atmosphere, B. Am. Meteorol. Soc., 79, 2101-2114, 1998.

Russell, P. B., Hobbs, P. V., and Stowe, L. L.: Aerosol properties and radiative effects in the United States East Coast haze plume: An overview of Tropospheric Aerosol Radiative Forcing Observational Experiment (TARFOX), J. Geophys. Res., 104, 2213 2222, 1999.

Saha, A. and Moorthy, K. K.: Impact of Precipitation on Aerosol Spectral Optical Depth and Retrieved Size Distributions: A Case Study, J. Appl. Meteorol., 43(6), 902-914, 2004.

Satheesh, S. K., Ramanathan, V., Jones, X. L., Lobert, J. M., Podogorny, I. A., Prospero, J. M., Holben, B. N., and Leob, N. G.: A Model for the natural and anthropogenic aerosols for the tropical Indian ocean derived from Indian ocean Experiment data, J. Geophys. Res., 104(D22), 27 421-27 440, 1999.

Satheesh, S. K. and Ramanathan, V.: Large differences in tropical aerosol forcing at the top of the atmosphere and Earths' surface, Nature, 405, 60-63, 2000.

Satheesh, S. K. and Srinivasan, J.: A mwthod to estimate radiative forcing from spectral optical depths, J. Atmos. Sci., 63, 1082 1092, 2006. 
Schwartz, S. E. and Andreae, M. O.: Uncertainty in climate change caused by aerosols, Science, 272, 1121-1122, 1996.

Shettle, E. P. and Fenn, R. W.: Models for the aerosols of the lower atmosphere and the effects of humidity variations on their optical properties. AFGL-TR-79-0214, Environmental research paper No. 676, Air Force Geophysics Laboratory, MA, USA, 94 pp, 1976.

Solomon, F., Giorgi, F., and Liousse, C.: aerosol modelling for regional climate studies: application to anthropogenic particles and evaluation over a European/African domain, Tellus, 58B, 51-72, 2006.

Takemura, T., Nakajima, H. T., Dubovik, O., Holben, B. N., and Kinne, S.: Single-scattering albedo and radiative forcing of various aerosol species with a global three-dimensional model, J. Climate, 15, 333-352, 2002.

Tripathi, S. N., Dey, S., Tare, V., and Satheesh, S. K.: Aerosol black carbon radiative forcing at an industrial city in northern India, Geophys. Res. Lett., 32, L08802, doi:10.1029/2005GL022515, 2005.

Twomey, S. A., Piepgrass, M., and Wolfe, T. L.: An assessment of pollution on global cloud albedo, Tellus, 36B, 356-366, 1984.
Vinoj, V., Babu, S. S., Satheesh, S. K., Moorthy, K. K., and Kaufman, Y. J.: Radiative forcing by aerosols over the Bay of Bengal region derived from ship borne, islandbased and satellite (Moderate-Resolution Imaging Spectroradiometer) observations, J. Geophys. Res., 109(D5), D05203, doi:10.1029/2003JD004329, 2004.

Vinoj, V. and Satheesh, S. K.: Measurements of aerosol optical depth over Arabian Sea during summer monsoon season, Geophys. Res. Lett., 30(5), 1263, doi:10.1029/2002GL016664, 2003.

Wild, M., Gilgen, H., Roesch, A., Ohmura, A., Long, C. N., Dutton, E. G., Forgan, B., Kallis, A., Russak, V., and Tsvetkov, A.: From Dimming to Brightening: Decadal Changes in Solar Radiation at Earth's Surface, Science, 308, 847-850, 2005.

$\mathrm{Xu}$, J., Bergin, M. H., Greenwald, R., and Russell, P. B.: Direct aerosol radiative forcing in the Yangtze delta region of China: Observation and model estimation, J. Geophys. Res., 108(D2), 4060, 7-1 to 7-12, doi:10.1029/2002JD002550, 2003.

Yu, S., Zender, C. S., and Saxena, V. K.: Direct radiative forcing and atmospheric absorption by boundary layer aerosols in the southeastern US: model estimates on the basis of new observations, Atmos. Environ., 35, 3967-3977, 2001. 